\title{
BORJA ALBI, Anabel. La traducción de los contratos internacionales desde la perspectiva del derecho comparado y la traductología. Granada: Comares, 2015, 168 pp. ISBN: 978-84- 9045-324-7.
}

Fruto del proyecto CDJ/GENTT (Borja Albi y Monzó, 2000), la autora abre nuevos horizontes en la edición de manuales de traducción jurídica por género textual con una base actualizada de derecho comparado. Este trabajo se podría enmarcar dentro de la jurilingüística, al cimentarse sobre una documentación factual que está pensada para el profesional de la traducción y reflexionar sobre las disparidades textuales a través de las que se articula la cultura y transcultura mercantil. De esta forma, profundiza en un solo tipo textual lo que, frente a los volúmenes genéricos de traducción y lenguaje jurídico en la combinación inglés-español (Alcaraz Varó, 1994 y Borja Albi, 2000) supone una ventaja por el grado de pertinencia y la integridad de la información que vierte. A pesar de que ya existen artículos de investigación o entradas de sitios webs especializados de gran calidad, como Traducción Jurídica, el formato libro permite una consulta rápida y contextualizada agrupando los distintos aspectos del contrato (desde el punto de vista histórico, cultural, profesional o estilístico) sin necesidad de navegar para cada consulta.

Por otro lado, el carácter didáctico de esta obra es indiscutible y se percibe por el tono, la estructuración y la disposición de la información que, al representarse en forma de cuadros sintetizadores, recoge los puntos de contenido de forma muy gráfica y agiliza su asimilación en un solo golpe de vista. Este aspecto es esencial para el traductor, tanto profesional, como aprendiz o investigador, ya que suele necesitar una rápida reconstrucción de las relaciones conceptuales dentro de cada campo.

Desde la introducción, Borja Albi indica que su volumen está pensado para "reforzar la competencia de transferencia" del mediador, aportando datos imprescindibles en el acto de comunicación que generan las transacciones comerciales. Intenta aliviar la complejidad que supone combinar los conocimientos temáticos, las diferencias entre sistemas jurídicos y políticos y recrear la fraseología propia del discurso contractual.

Su proyecto dota de profundidad al acto de producir equivalencias en el terreno resbaladizo del derecho, tan impregnado del componente cultural. Asimismo, al tratarse en la mayor parte de los casos de una traducción patente, cede más protagonismo al texto y cultura origen, con la intención de que la primera parte del proceso traductor, la comprensión, se desarrolle de forma efectiva. De ahí que de los ocho capítulos de los que consta el libro, dos de los más extensos, el 3 y 4, estén destinados al análisis del género contractual anglosajón y que la redacción española solo se recoja de 
forma contrastiva (capítulo 5). Borja Albi sigue la tradición de la búsqueda de la fidelidad y la tendencia a la literalidad en la traducción jurídica por las características de este campo especializado pero, al igual que Mayoral Asensio (2013), matiza: "se puede ser fiel al significado, a las palabras, al estilo o al formato" (página 107). La literalidad excesiva puede provocar un efecto completamente contrario, de consecuencias nefastas. Por consiguiente, la autora vuelve a situar el encargo de traducción en el centro del método de trasvase y recomienda establecer prioridades de traducción en función del mismo. Ciertamente, las dificultades relacionadas con este campo temático y con la falta de correspondencias terminológicas y conceptuales solo pueden resolverse con un buen conocimiento de los sistemas jurídicos (Borja, 2000; Engberg, 2013); por ello su obra suple las carencias del traductor no jurista y del jurista traductor que necesita reciclar conocimientos o desconoce los usos y costumbres del mundo mercantil anglosajón.

Otro aspecto indispensable de la presente obra, que supera la dicotomía de sistemas jurídicos en espejo, es la descripción del contexto internacional de la contratación mercantil que se recoge en el capítulo 1. En la elaboración de materiales sobre traducción para el máster en Lenguas, Culturas y Relaciones Comerciales con África y Asia del ISTRAD, coincidimos con ese planteamiento. El reciclaje de la indómita Lex Mercatoria, derecho internacional disperso basado en la praxis y, desde antaño, transfronterizo, hace necesaria la inserción de una descripción del complejo entramado de reglas escritas y no escritas que gobiernan el mercado internacional y que, por supuesto, tienen consecuencias en la elaboración, interpretación y translación de contratos. La autora explica, con gran capacidad de síntesis y de forma accesible, las iniciativas dirigidas a dotar de seguridad jurídica a los contratos y disminuir los costes de transacción internacionales como los INCOTERMS y los principios UNIDROIT. Tales proyectos, sumados al Convenio de Roma o las organizaciones internacionales como la Cámara de Comercio Internacional, la UNCITRAL, la UE (a través de los Principios de Derecho Europeo de los Contratos 0 el futuro Código Europeo de Contratos) o los contratos-tipo FICIC y ORGALIME resultan tremendamente útiles para el traductor, en especial, cuando se generan versiones textuales multilingües. Por ello la contextualización inicial del monográfico tiene un doble uso: como enciclopedia de cabecera y conglomerado de sitios web fiables de textos paralelos y recursos terminológicos.

En los capítulos 2 y 3 se relatan las disparidades jurídicas del derecho de contratos anglosajón y español, como la ausencia de una tipología reglada en el primero, al tiempo que se describe con lujo de detalles el clausulado estereotipado del contrato inglés. Sobre el esquema 
trazado por Alcaraz (1994), Mayoral Asensio (2007) y, sobre todo, Cuñado y Gámez (2013), Borja Albi amplía la información del texto de partida antes de cotejarlo con los modelos de llegada: alude a la función complementaria de los recitals, subclasifica las definitions, incorpora las "condiciones previas" que establecen los requisitos que se deben cumplir para que el contrato sea válido, ahonda en las cláusulas operativas y aborda formas contractuales especiales como las letters of agreement y las deeds. La principal virtud de esta parte del manual es la incorporación de información pragmática que entrelaza la netamente jurídica y la lingüística. Así, en pocas líneas, el traductor puede aumentar su competencia temática y activar la estratégica, sintiéndose parte vital del acto performativo. Veamos un par de ejemplos:

(...) otra práctica habitual de los vendedores es incluir una cláusula requiriendo al comprador que firme un albarán de entrega en el que se indica que las mercancías han sido entregadas según lo dispuesto en el contrato y que, por tanto, el comprador las acepta. Estos albaranes suelen firmarlos los encargados de almacén u otros empleados que no conocen el contenido del contrato (página 74).

Sin embargo, puede ocurrir que el comprador haya elegido a su proveedor porque confía en la calidad de sus productos y no esté dispuesto a aceptar que el proveedor sea otra empresa distinta a la que eligió. Para evitar que esta situación se produzca, puede insertar una cláusula como la siguiente (...) [en referencia a la cesión de derechos] (página 80).

En el capítulo 4, se reflexiona sobre la complejidad que entraña el trasvase de la jerga jurídica, que no solo varía entre el sistema common law y el continental, sino también entre los países dentro de la misma tradición jurídica, verbigracia, en el caso de la propiedad y posesión. Se retoman las características del lenguaje de especialidad del campo del derecho en los idiomas del presente manual y se precisan en el género contractual cuyo vocabulario se torna más innovador debido a los cambios que impone el comercio y a los intentos de armonización internacional del derecho mercantil.

Por otro lado, se añade la visión textual, que nos devuelve un contrato más pormenorizado anglosajón frente al español. Se introduce en este epígrafe la macroestructura de contrato hispano que, al cotejo descriptivo, refuerza la hipótesis de partida: hay diferencias de formato y vacío conceptual y terminológico de algunas de las cláusulas inglesas estereotipadas. En este sentido, Borja Albi se inclina hacia el mantenimiento del original como indica en obras anteriores (página 98).

En esta sección la autora realiza anotaciones de tipo traductológico: recoge falsos amigos, recomienda cómo traducir las expresiones sufijadas y 
contextualiza la presencia de los dobletes en el contrato inglés aunque, en este caso, no aporta soluciones dadas en español. Dicho contenido sirve de pasarela hasta el capítulo 5, que versa sobre la traducción de los contratos. En él se da relevancia a la lengua como herramienta principal de difusión y registro del derecho y se plantea el problema de la interpretación que la investigadora resuelve sentenciado que, más allá de la lengua que se emplee en la redacción, debería indicarse la específica según la cual se tendrán que decodificar los términos léxicos y gramaticales empleados en la redacción ( $p$. e. el inglés americano). También expone la existencia de contratos multilingües en los que ha de indicarse la equidad o no de las lenguas 0 , incluso, crear un comité de seguimiento lingüístico.

En este apartado reúne esquemáticamente las restricciones textuales y extratextuales de la traducción e incide en la necesidad de ajustar la elección de las soluciones de translación a las circunstancias, efecto y receptores meta para evitar la incomprensión del texto meta. Todos los capítulos anteriores nutren al traductor para lograr superar ese reto con el que concluye su trabajo (capítulo 6), que completa con el tema 7, dedicado a los recursos documentales, como el corpus, herramienta indispensable para la traducción jurídica de calidad, y los anexos bibliográficos que, aparte de las referencias empleadas, ofrecen instrumentos legislativos sobre comercio internacional, un listado de diccionarios jurídicos y comerciales y una muestra, a título ilustrativo, de bitextos de traducciones sancionadas por la UE y la UNCTAD.

Habida cuenta de lo indicado anteriormente, sin duda alguna el manual de Borja Albi es una herramienta que no debe faltar en la estantería del traductor jurídico puesto que permite tomar decisiones de translación contractual informada, adquirir una buena metodología de trabajo y seguir profundizando en el conocimiento del campo. Se trata de una auténtica joya para el lingüista con carencias de derecho comercial o el jurista que desea abrirse camino en el mercado internacional o en instituciones multilingües.

[MARÍA LUISA RODRÍGUEZ MUÑOZ] 